\title{
Pengaruh Perubahan Tata Guna Lahan Terhadap Debit Saluran Drainase Jalan Arifin Ahmad Pada Ruas Antara Jalan Rambutan Dengan Jalan Paus Ujung Di Kota Pekanbaru
}

\author{
The Effect of Changes in Land Use on the Discharge of Drainage Channels on Jalan Arifin \\ Ahmad on the Section Between Jalan Rambutan and the Jalan Paus in the City of Pekanbaru
}

\author{
Arie Setyawan ${ }^{1}$, Anas Puri' ${ }^{2}$, Harmiyati ${ }^{3}$ \\ ${ }^{1}$ Mahasiswa Program Studi Teknik sipil, Universitas Islam Riau \\ rieagain93@gmail.com; \\ 2,3Pengajar Program Studi Teknik sipil, Universitas Islam Riau \\ anaspuri@eng.uir.ac.id;
}

\begin{abstract}
Abstrak
Perkembangan kota yang diikuti dengan meningkatnya jumlah penduduk di Kota Pekanbaru menyebabkan terjadi alih fungsi lahan menjadi areal pemukiman ataupun perkantoran. Adanya perubahan fungsi lahan dari areal hijau menjadi areal pemukiman atau perkantoran mengakibatkan terganggunya daya resap tanah sehingga aliran permukaan (run off) menjadi semakin besar.

Tujuan dari penelitian ini adalah unutuk mengetahui kemampuan saluran drainase Jalan Arifin Ahmad dalam menampung debit aliran dengan pengaruh perubahan tataguna lahan dalam 10 tahun yang akan dating dan mengetahui penyebab dari tergenangnya air pada salah satu ruas Jalan Arifin Ahmad tepat nya pada ruas antara Jalan Rambutan dengan Jalan Paus Ujung. Pada penelitian ini dilakukan perhitungan frekuensi curah hujan menggunakan jenis uji distribusi Log-Pearson III. Intensitas curah hujan dihitung menggunakan metode rasional. Debit rencana $(\mathrm{Qr})$ berdasarkan jumlah debit hujan $(\mathrm{Qh})$, debit air kotor $(\mathrm{Qk})$ dan debit kiriman $\left(\mathrm{Q}_{\text {Kiriman }}\right)$. Perubahan tata guna lahan mengacu kepada RTRW kota pekanbaru, kapasitas saluran drinase dihitung menggunakan persamaan manning, dan selanjutnya di analisa apakah saluran tersebut masih mampu menampung debit rencana 10 tahun mendatang dengan perubahan tata guna lahan yang ada.

Dari hasil analisa debit rencana 10 tahun mendatang adalah 2,74 $\mathrm{m}^{3} /$ detik dengan debit saluran (Qs) sebesar = $0,97 \mathrm{~m}^{3} /$ detik untuk saluran tanah dan $2,34 \mathrm{~m}^{3} /$ detik untuk saluran permanen, maka dapat disimpulkan bahwa saluran eksisting drainase Jalan Arifin Ahmad pada ruas antara Jalan Rambutan dengan Jalan Puas Kota Pekanbaru tidak aman. Adapun dimensi saluran drainase rencana 10 tahun mendatang adalah lebar dasar saluran $(B)=3,5 \mathrm{~m}$, tinggi permukaan air $(\mathrm{h})=1,75 \mathrm{~m}$, tinggi jagaan air $(\mathrm{w})=0,25 \mathrm{~m}$, dan tinggi saluran $(\mathrm{H})=2 \mathrm{~m}$. Faktor-faktor penyebab terjadinya genangan air pada salah satu ruas Jalan Arifin Ahmad tepatnya pada ruas antara Jalan Rambutan dengan Jalan Paus Ujung adalah tidak mengalirnya air dari badan jalan ke saluran drainase akibat kurang berfungsinya tali air sebagai tempat mengalirnya air hujan dari badan jalan ke saluran drainase, banyaknya sampah dan lumpur yang menyebabkan penyumbatan aliran air pada saluran drainase. Adapun faktor utama nya adalah debit rencana aliran lebih besar dari pada debit saluran eksisting, dimana debit rencana aliran $(\mathrm{Qr})=2,32 \mathrm{~m}^{3} /$ detik, debit saluran tanah eksisitng $(\mathrm{Qs})=0,97 \mathrm{~m}^{3} / \mathrm{detik}$, dan debit saluran permanen eksisting $(\mathrm{Qs})=2,34 \mathrm{~m}^{3} /$ detik.
\end{abstract}

Kata Kunci: Tata Guna Lahan, Drainase, Debit Rencana, RTRW, Intensitas Hujan

\section{Abstract}

The development of the city followed by the increasing number of residents in the city of Pekanbaru causing the conversion of land into residential areas or offices. The change of land function from green area to residential area or offices resulted in disturbance of soil absorption so that runoff becomes bigger.The purpose of this research is to know the ability of drainage channel Arifin Ahmad Road in accommodating flow discharge with the effect of land use change in 10 years that will come and know the cause of the water flooding on one of Arifin Ahmad Road segment right on the road between Jalan Rambutan with Jalan Pope Edge. In this research is calculated the frequency of rainfall using the type of Log-Pearson III distribution test. Rainfall intensity is calculated using rational methods. The plan debit (Qr) is based on the amount of rainfall (Qh), gross discharge (Qk) and debit of mail (QKiriman). Land use change refers to RTRW kotabaru, drainage channel capacity is 
calculated using the manning equation, and then analyzed whether the channel is still able to accommodate the discharge of the next 10 years plan with changes in existing land use.From the results of the next 10 years plan debit analysis is $2.74 \mathrm{~m} 3$ / second with the channel discharge (Qs) of $0.97 \mathrm{~m} 3 / \mathrm{sec}$ for the ground channel and $2.34 \mathrm{~m} 3$ / sec for the permanent channel, it can be concluded that the drainage existing channel Arifin Ahmad Road on the segment between Jalan Rambutan and Jalan Puas Pekanbaru is not safe. The dimensions of the drainage channel of the plan for the next 10 years are the bottom width of the channel $(\mathrm{B})=3.5 \mathrm{~m}$, the water level $(\mathrm{h})=1.75 \mathrm{~m}$, the water velocity $(\mathrm{w})=0.25 \mathrm{~m}$, and the channel height $(\mathrm{H})=2 \mathrm{~m}$. The factors causing water puddle on one of Arifin Ahmad Road segment precisely on the road between Rambutan Street and Ujung Pope Road is not the flow of water from the road to the drainage channel due to the lack of functioning of the water line as a place of rain water flow from the road to the drainage channel, the amount of garbage and mud that causes blockage of water flow in the drainage channel. The main factor is the flow of the flow plan is greater than the existing channel discharge, where the flow of the flow plan $(\mathrm{Qr})=2.32 \mathrm{~m} 3 / \mathrm{sec}$, the discharge of the exisiting ground channel $(\mathrm{Qs})=0.97 \mathrm{~m} 3 / \mathrm{sec}$, and the permanent channel discharge Existing $(\mathrm{Qs})=2.34 \mathrm{~m} 3 /$ sec.

Keywords: Land Use, Drainage, Plan Debit, RTRW, Rain Intensity

\section{PENDAHULUAN}

Permasalahan melimpahnya air drainase adalah hal yang biasa yang sering di alami setiap musim hujan terjadi. Keterbiasaan ini mengakibatkan masalah drainase dianggap bukan persoalan yang penting. Genangan banjir baru dianggap mengganggu bila sudah menyebabkan lumpuhnya aktivitas lalu lintas karena badan jalan sudah digenangi air dan tidak bisa lagi dilalui.

Perkembangan kota yang diikuti dengan meningkatnya jumlah penduduk di Kota Pekanbaru menyebabkan terjadi alih fungsi lahan menjadi areal pemukiman ataupun perkantoran. Adanya perubahan fungsi lahan dari areal hijau menjadi areal pemukiman atau perkantoran mengakibatkan terganggunya daya resap tanah sehingga aliran permukaan (run off) menjadi semakin besar. Pada akhirnya kondisi inilah yang menyebabkan timbulnya genangan di beberapa ruas jalan di Kota Pekanbaru, khususnya pada salah satu ruas Jalan Arifin Ahmad. Kita tahu bahwa dulunya Jalan Arifin Ahmad dikelilingi areal hijau perpohonan, bangunan-bangunan masih sedikit, akan tetapi saat ini bangunan ruko memenuhi pinggiran Jalan Arifin Ahmad, semakin pesat nya pertumbuhan penduduk memaksa areal hijau disekitaran Jalan Arifin Ahmad dibangun perumahan-perumahan mulai dari type sederhana hingga perumahanperumahan elite sekalipun. Karena nya debit limpasan yang ada sudah tidak dapat lagi tertampung oleh kapasitas saluran drainase eksisting. Tujuan dari penelitian ini adalah untuk mengetahui kemampuan saluran drainase Jalan Arifin Ahmad dalam menampung debit aliran dengan pengaruh perubahan tataguna lahan dalam 10 tahun yang akan datang.

\subsection{Tinjauan Pustaka}

Bahri (2017), telah melakukan penelitian tentang "Analisa Pengaruh Perubahan tata Guna Lahan Terhadap Kapasitas Drainase Di Jl. Arengka Kota Pekanbaru (Studi Kasus Pasar Pagi Arengka)". Tujuan dari penelitian ini adalah menganalisa kemampuan eksisting saluran drainase yang berada di Pasar pagi Arengka Kecamatan Marpoyan Damai Kota Pekanbaru, apakah eksisting saluran drainase mampu untuk menanmpung debit rencana aliran maksimum. Dalam menganalisa kemampuan eksisting saluran drainase Pasar Pagi Arengka penulis mengacu pada: (1). Data curah hujan, (2). Data limbah domestic. Adapun perhitungan debit rencana (Qr) dihitung dengan menggunakan metode rasional dan juga berdasarkan jumlah debit hujan (Qh) dengan debit air kotor (Qk). Frekuensi curah hujan dianalisa menggunakan jenis uji distribusi LogPerson III. Intensitas curah hujan dihitung dengan menggunakan metode rasional. Debit air kotor dianalisa berdasarkan ketentuan Dirjen Cipta Karya DPU. Kapasitas saluran drainase dihitung dengan menggunakan rumus manning, dan selanjutnya kapasitas saluran drainase 
tersebut dievaluasi apakah saluran eksisting mampu atau tidak untuk menampung debit limpasan yang terjadi. Dari hasil analisa besar debit rencana aliran pada saluran drainase Pasar Pagi Arengka Kecamatan Marpoyan Damai Kota Pekanbaru adalah 2,8104 m3/detik, sedangkan besar debit saluran adalah 0,54 m3/detik. Hasil analisa curah hujan maksimum dan limpasan warga adalah, lebar dasar saluran $(B)=2,0 \mathrm{~m}$, tinggi saluran $(\mathrm{H})=1,7 \mathrm{~m}$. berdasakan hasil analisa dan perhitungan dapat disimpulkan bahwa kondisi eksisting saluran drainase Pasar pagi Arengka Kecamatan Marpoyan Damai Kota Pekanbaru pada saat ini tidak aman terhadap intensitas hujan yang tinggi dan juga pengaruh dari perubahan guna lahan yang terjadi di Pasar Pagi Arengka. Oleh karena itu dimensi eksisting drainase perlu didesain ulang.

\subsection{Landasan Teori Intensitas Hujan}

Intensitas hujan adalah tinggi atau kedalaman air hujan per satuan waktu. Sifat umum hujan adalah makin singkat hujan berlangsung intensitasnya cenderung makin tinggi dan makin besar periode ulangnya makin tinggi pula intensitasnya. Hubungan antara intensitas, lama hujan, dan frekuensi hujan biasanya dinyatakan dalam lengkung Intensitas Durasi Frekuensi (IDF).

Besarnya intensitas hujan berbeda-beda tergantung dari lamanya curah hujan dan frekuensi kejadiannya. Menurut Mononobe, intensitas curah hujan (I) pada rumus rasional dapat dihitung dengan persamaan seperti dibawah ini.

$$
\begin{aligned}
& I=\frac{R_{24}}{24}\left(\frac{24}{t_{c}}\right)^{\frac{2}{3}} \\
& \text { Dimana: } \\
& I=\text { Intensitas hujan }(\mathrm{mm} / \mathrm{jam}) \\
& R=\text { Curah hujan maksimum } \\
& \text { (mm) } \\
& t_{c} \quad=\text { Waktu konsentrasi }
\end{aligned}
$$

\section{Koefisien Pengaliran (C)}

Koefisien pengaliran permukaan (C) merupakan bilangan yang menunjukkan besarnya aliran permukaan dengan besarnya curah hujan yang dipengaruhi oleh tata guna lahan. Nilai $\mathrm{C}$ berkisar antara 0 sampai 1, semakin baik kondisi lahan maka nilai $\mathrm{C} \approx 0$ di artikan hampir semua air hujan yang terinfiltrasi. Jika kondisi daerah tangkapan semakin buruk maka nilai $\mathrm{C} \approx 1$, di artikan bahwa sedikitnya air yang terinfiltrasi dan mengakibatkan aliran permukaan semakin tinggi. Kawasan yang terdiri dari berbagai macam penggunaan lahan dengan koefisien aliran permukaan yang berbeda, maka nilai $\mathrm{C}$ yang digunakan adalah koefisien kawasan yang dapat dihitung dengan menggunakan persamaan dibawah ini.

$$
\begin{aligned}
& \mathrm{C}_{\text {DAS }}=\frac{\sum_{\mathrm{i}=1}^{\mathrm{n}} \mathrm{C}_{\mathrm{i}} \mathrm{A}_{\mathrm{i}}}{\sum_{\mathrm{i}-1}^{\mathrm{n}} \mathrm{A}_{\mathrm{i}}} \\
& \text { Dimana: } \\
& A_{i} \quad=\text { luas lahan dengan jenis } \\
& \text { penutup tanah } i \\
& C_{i} \quad=\text { koefisien aliran permukaan } \\
& \text { jenis penutup tanah } i \\
& n \quad=\text { jumlah jenis penutup lahan }
\end{aligned}
$$

Harga koefisien aliran permukaan jenis penutup tanah (C) tergantung pada sifat dan kondisi tanah. Laju infiltrasi menurun pada hujan yang terus menerus dan juga dipengaruhi oleh kondisi kejenuhan air sebelumnya.

\section{Analisa Debit Air Kotor}

Debit air kotor adalah air hasil aktifitas manusia berupa air buangan rumah tangga. Dalam perhitungan analisa debit air kotor, kita perlu mengetahui besarnya kebutuhan air penduduk dalam tiap-tiap wilayah yang ditinjau.

Dari jumlah pemakaian air tersebut dapat diperkirakan besarnya air buangan yang harus ditampung dan dialirkan yaitu sebesar $85 \%$ dari kebutuhan air yang ditetapkan (Suhardjono, 2013). Dengan mengetahui jumlah pemakaian air, maka debit aliran air kotor dapat dihitung dengan menggunakan persamaan dibawah ini:

$$
\mathrm{Q}_{\mathrm{k}}=\frac{\mathrm{P}_{\mathrm{n}} \times \mathrm{q}}{\mathrm{A}}
$$

Dimana:

$$
\begin{aligned}
Q_{k}= & \text { debit air kotor rata-rata } \\
& \left(\text { liter } / \text { detik } / \mathrm{m}^{2}\right)
\end{aligned}
$$




$$
\begin{aligned}
& P_{n}=\text { jumlah penduduk } \\
& q=\text { debit air buangan } \\
& \quad \text { (liter/detik/orang) } \\
& A=\text { luas total wilayah }\left(\mathrm{m}^{2}\right)
\end{aligned}
$$

\section{Analisa Debit Rencana Aliran}

Ketetapan dalam menetapkan besarnya debit air yang harus di alirkan melalui saluran drainase pada daerah tertentu sangatlah penting dalam penentuan dimensi saluran. Dimensi saluran yang terlalu besar akan memiliki nilai yang tidak ekonomis, namun bila terlalu kecil akan mempunyai tingkat ketidak berhasilan yang tinggi.

Menghitung besarnya debit rencana pada umumnya dilakukan dengan metode rasional. Hal ini karena luasan daerah aliran tidak terlalu luas, kehilangan air sedikit dan waktu konsentrasi relatif pendek.

Kapasitas pengaliran dapat dihitung dengan menggunakan metode rasional sebagai berikut:

$\mathrm{Q} \quad=0,002778 \times \mathrm{C} \times \mathrm{I} \times \mathrm{A} \cdots \cdots \cdots(3.16)$

Dimana:

$$
\begin{aligned}
Q \quad= & \text { kapasitas pengaliran } \\
& \left(\mathrm{m}^{3} / \mathrm{det}\right) \\
C & = \\
I & \text { koefisien pengaliran } \\
& \text { intensitas curah hujan } \\
& (\mathrm{mm} / \mathrm{jam}) \\
A \quad= & \text { luas daerah pengaliran } \\
& \text { (Ha) }
\end{aligned}
$$

\section{METODE PENELITIAN}

\subsection{Lokasi Penelitian}

Lokasi penelitian ini dilakukan di Jalan Arifin Ahmad Kecamatan Marpoyan Damai Kota Pekanbaru, secara geografis terletak pada $0{ }^{0} 00$ '28" LU dan 101 00'25" BT. Kecamatan Marpoyan Damai berbatasan lansung dengan :

1. Sebelah Utara : Kecamatan Payung Sekaki dan Kecamatan Sukajadi

2. Sebelah Selatan : Kabupaten Kampar

3. Sebelah Timur : Kecamatan Bukit Raya

4. Sebelah Barat : Kecmatan Tampan

Lokasi penelitian ini dimulai dari persimpangan Jalan Rambutan yang berada di sebelah barat lokasi penelitian sampai di depan persimpangan Jalan Paus Ujung.
Untuk lebih jelasnya lokasi penelitian dapat dilihat pada gambar 1.

\section{Teknik Pengumpuan Data}

Adapun cara pengumpulan data dalam penelitian ini adalah sebagai berikut:

1. Data Primer: Observasi lapangan, mengukur dimensi eksisting saluran drainase Jalan Arifin Ahmad, baik saluran permanen dan saluran tanah, mengukur dimensi area limpasan pada daerah yang distudikan, seperti dimensi limpasan warga, jalan, dan bahu jalan

2. Pengumpulan Data Sekunder: memperoleh data jumlah penduduk dengan cara wawancara, seperti RT dan penghuni Ruko atau Kantor. Data curah hujan pada penelitian ini diperoleh dari Stasiun Meteorologi dan Geofisika Kota Pekanbaru dengan panjang data curah hujan 15 tahun (2002-2016). Data RTRW pada penelitian ini diperoleh dari Dinas Tata Ruang Kota Pekanbaru tahun 2014-2034.

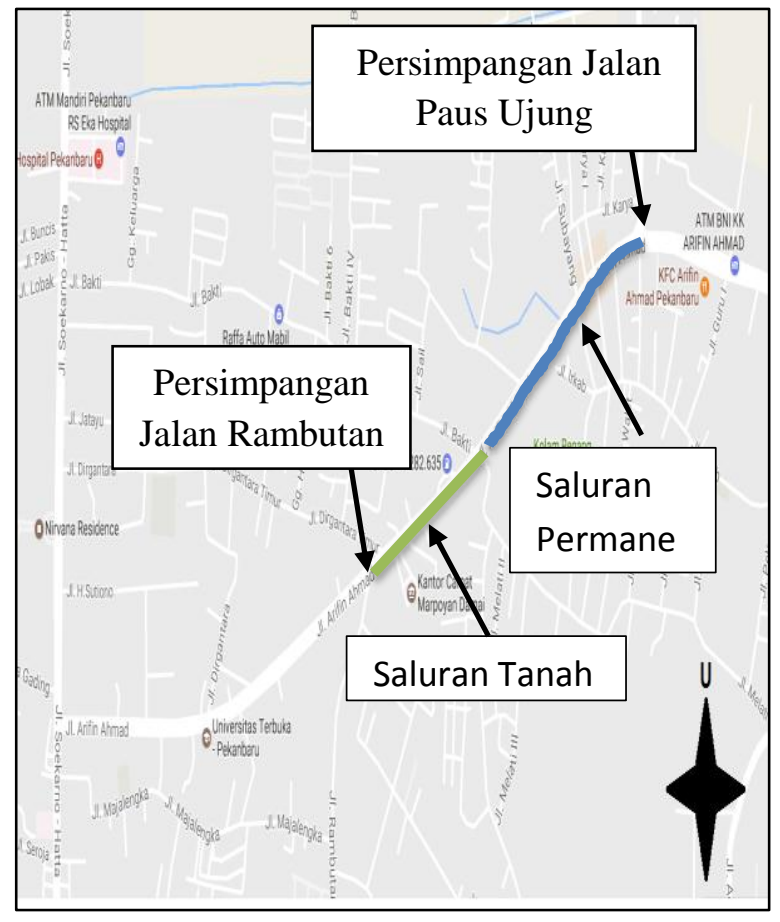

Gambar 1. Peta lokasi penelitian

\subsection{Tahap Pelaksanaan Penelitian}

Pada Tahap ini memperlihatkan gambaran secara garis besar langkah-langkah penelitian untuk menuntun penulis agar 
penelitian ini lebih terarah yang dapat dilihat pada gambar 2 .

Tahapan penelitian sebagai berikut:

1. Persiapan

Persiapan yang dilakukan adalah, menyiapkan alat-alat untuk pengukuran dimensi saluran dan dimensi limpasan, seperti meteran, kamera, kertas, pulpen dll.

2. Pengumpulan Data

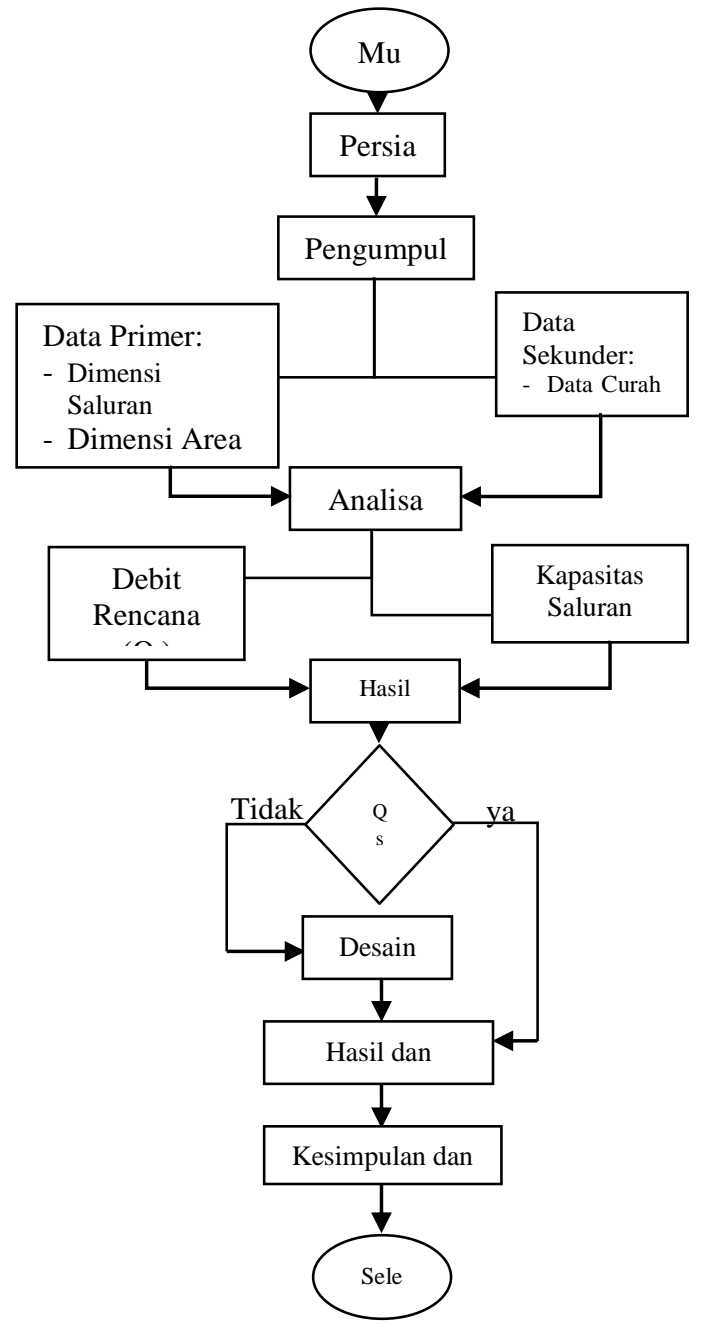

Gambar 2. Bagan alir penelitian

Data-data yang diperlukan adalah data primer dan data sekunder seperti yang telah dijelaskan sebelumnya.

1. Analisa Data

Setelah data-data yang diperlukan terkumpul, kemudian dilakukan pengolahan dan analisa data. Adapun tahap-tahap dalam menganalisa perhitungan ini yaitu: menghitung frekuensi curah hujan, m menghitung intensitas curah hujan, menghitung debit aliran, menghitung debit saluran dan redesign saluran

2. Hasil dan Pembahasan

Pada tahap ini akan dilakukan perbandingan hasil analisa data dengan debit saluran.

3. Kesimpulan dan Saran

Kesimpulan dan saran merupakan tahap akhir dari hasil analisa dan pembahasan dari penelitian yang dilakukan.

\subsection{Cara Analisis}

Menganalisis data ini menggunakan beberapa metode unutk mendapatkan beberapa pembahasan permasalahan yang terjadi dilokasi penelitian. Adapun tahaptahap yang dilakukan diantaranya:

1. Menghitung frekuensi curah hujan.

Dasar perhitungan distribusi frekuensi adalah parameter yang berkaitan dengan anlisis data yang meliputi rata-rata, simpangan baku, koefisien variansi, dan koefisien kemencengan.

2. Menghitung intensitas curah hujan menggunakan rumus rasional.

Intensitas curah hujan (I) pada rumus rasional dapat dihitung dengan persamaan $\mathrm{I}=\frac{\mathrm{R}_{24}}{24}\left(\frac{24}{\mathrm{t}_{\mathrm{c}}}\right)^{\frac{2}{3}}$

3. Menghitung debit aliran eksisting

Debit aliran berbanding lurus dengan koefisien pengaliran (C), intensitas curah hujan (I), dan luas daerah pengaliran (A).

4. Menghitung debit aliran terkait perubahan tata guna lahan

Perubahan tata guna lahan tentunya mempengaruhi besar nya koefisien pengaliran (C) dan juga mempengaruhi persentase penggunahan lahan, sesuai dengan RTRW yang ada untuk menghitung debit air kotor, sehingga didapatlah debit aliran 10 tahun mendatang.

5. Menghitung kapasitas saluran drainase. Untuk menghitung kapaasitas saluran diperlukan data luas penampang saluran (A) dan kecepatan aliran (V) berdasarkan jenis saluran karena kapasitas saluran berbanding lurus dengan luas penampang dan kecepatan alirannya. 
6. Mengevaluasi bangunan saluran drainase.

Diketahui nya debit aliran dan debit saluran maka bangunan saluran drainase dapat di evaluasi, jika debit aliran lebih besar dari debit saluran (Qr < Qs) maka bangunan saluran drainase dinyatakan aman sedangkan jika debit aliran lebih besar dari debit saluran (Qr > Qs) maka bangunan saluran drainase tidak aman perlu direncanakan ulang

7. Merencanakan saluran.

Setelah mendapatkan debit aliran rencana dan jenis saluran yang akan direncanakan maka luas penampang basah (A) bias dihitung berikut dengan kedalahan air (h), lebar dasar aliran (b), lebar atas saluran (B), kemiringan (I) dan tinggi jagaan (w) berdasarkan rumus manning.

8. Menganalisa faktor pendukung kejadian banjir.

Selain faktor saluran yang tidak bias menampung debit aliran yang bisa mengakibatkan genangan ataupun banjir, faktor pendukung lainnya perlu diperhatikan, maka perlu nya tinjauan lansung ke daerah yang di teliti.

\section{HASIL DAN PEMBAHASAN} Analisa Frekuensi Hujan

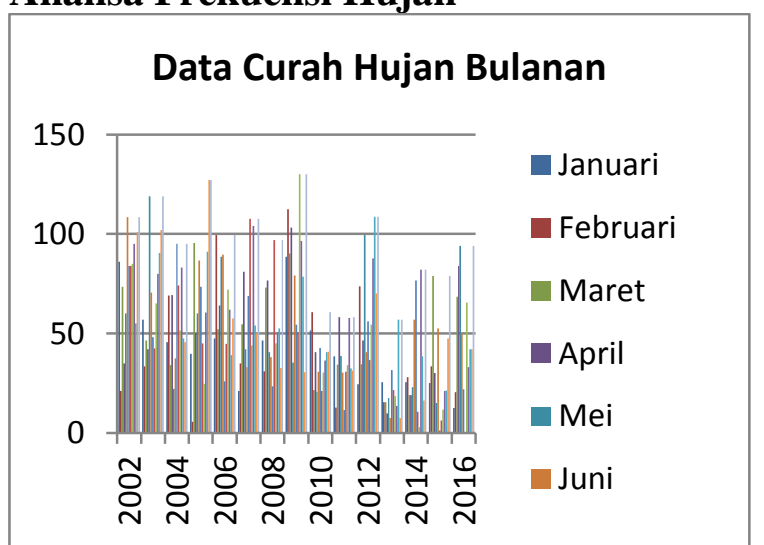

Gambar 3. Data Curah Hujan Bulanan

Maksimum

Data curah hujan yang diperoleh selama 15 tahun, maka dapat diketahui besarnya curah hujan rencana dengan menggunakan uji distribusi Log-Pearson III sebagai berikut:
1. Rata-rata Logaritma $=1,832$
2. Simpangan baku $=0,18$
3. Koefisien kemencengan $=1,4$

Besarnya curah hujan rencana dengan mengunakan jenis uji distribusi LogPearson III pada Tabel 1.

Tabel 1. Curah hujan rencana

\begin{tabular}{|c|c|c|c|c|}
\hline 吾 & 2 & 5 & 10 & 25 \\
\hline $\begin{array}{l}\mathbf{X}_{\mathrm{T}}= \\
\mathbf{R}\end{array}$ & $\begin{array}{c}61,806 \\
\mathrm{~mm}\end{array}$ & $\begin{array}{c}90,872 \\
\mathrm{~mm}\end{array}$ & $\begin{array}{c}118,085 \\
\mathrm{~mm}\end{array}$ & $\begin{array}{c}163,898 \\
\mathrm{~mm}\end{array}$ \\
\hline
\end{tabular}

\section{Intensitas Curah Hujan}

Adapun perhitungan waktu konsentrasi pada penelitian ini sesuai dengan perencanaan saluran drainase yakni pada sisi sebelah selatan Jalan Arifin Ahmad Kecamatan Marpoyan Damai Kota Pekanbaru dengan panjang saluran $1.042 \mathrm{~m}$, dideskripsikan pada Gambar 4

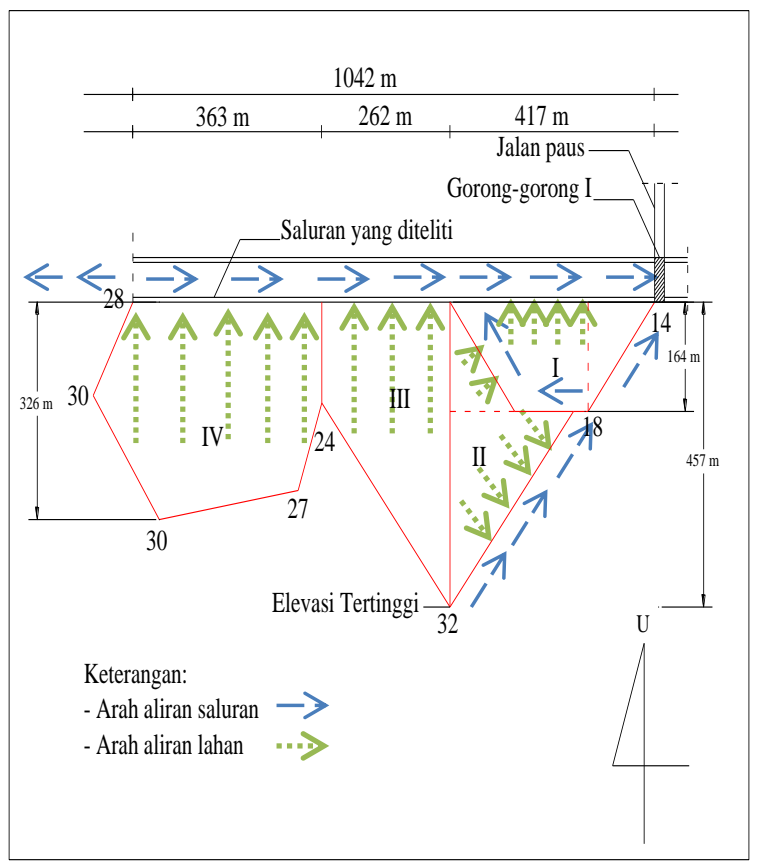

Gambar 4. Catchment Area Jalan Arifin Ahmad

Berdasarkan hasil perhitungan waktu konsentrasi $\left(t_{c}\right)$ pada kawasan perencanaan saluran drainase Jalan Arifin Ahmad pada ruas Jalan Rambutan dengan Jalan Paus sebesar 0,59 jam dan diperolehnya curah hujan rencana untuk kala ulang 10 tahun, maka besarnya intensitas curah hujan yang terjadi dikawasan Jalan Arifin Ahmad pada 
ruas Jalan Rambutan dengan Jalan Paus dapat dihitung seperti dibawah ini:

$$
\begin{aligned}
I & =\frac{R_{24}}{24}\left(\frac{24}{t_{c}}\right)^{\frac{2}{3}} \\
= & \frac{118,085}{24}\left(\frac{24}{0,59}\right)^{\frac{2}{3}} \\
& =58,2 \mathrm{~mm} / \mathrm{jam}
\end{aligned}
$$

\section{Debit Air Kotor}

Dari jumlah pemakaian air dapat diperkirakan besarnya air buangan masyarakat yang harus ditampung dan dialirkan melalui saluran drainase Jalan Arifin Ahmad pada ruas Jalan Rambutan dengan Jalan Paus pada Tabel 2.

Tabel 2. Air buangan masyarakat eksisting

\begin{tabular}{|c|c|c|}
\hline $\begin{array}{c}\text { Pemakaian } \\
\text { Air } \\
\text { (liter) }\end{array}$ & $\begin{array}{c}\text { Besar Air } \\
\text { Buangan } \\
\text { (liter) }\end{array}$ & $\begin{array}{c}\text { Debit Air } \\
\text { Kotor } \\
\left(\mathbf{m}^{3} / \text { detik }\right)\end{array}$ \\
\hline 409.770 & $348.304,50$ & 0,00141 \\
\hline
\end{tabular}

Debit air kotor pada 10 tahun mendatang dapat kita hitung dengan mengacu kepada persentase penggunaan lahan pada catchment area. Dari jumlah pemakaian air tersebut dapat diperkirakan besarnya air buangan masyarakat yang harus ditampung dan dialirkan melalui saluran drainase Jalan Arifin Ahmad pada ruas Jalan Rambutan dengan Jalan Paus untuk 10 tahun mendatang dapat dilihat pada Tabel 3.

Tabel 3. Air buangan masyarakat 10 tahun mendatang

\begin{tabular}{|l|l|l|}
\hline $\begin{array}{l}\text { Pemakaian } \\
\text { Air } \\
\text { (liter) }\end{array}$ & $\begin{array}{l}\text { Besar Air } \\
\text { Buangan } \\
\text { (liter) }\end{array}$ & $\begin{array}{l}\text { Debit Air } \\
\text { Kotor } \\
\left(\mathbf{m}^{3} \text { /detik }\right)\end{array}$ \\
\hline 575250 & 488962,5 & 0,00198 \\
\hline
\end{tabular}

\section{Debit Aliran}

Analisa debit aliran dipengaruhi oleh koefisien pengaliran, intensitas curah hujan, luas daerah tangkapan hujan dan besarnya debit air kotor yang masuk ke saluran tersebut. Perhitungan analisa debit aliran menggunakan metode rasional, hasil debit

\begin{tabular}{|c|c|c|c|c|c|}
\hline \multirow[b]{2}{*}{ NO } & \multirow[b]{2}{*}{ Nama Saluran } & \multicolumn{3}{|c|}{ Debit Aliran } & \multirow[b]{2}{*}{ } \\
\hline & & 跑 & 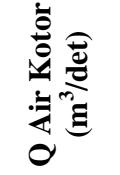 & 焉 & \\
\hline 1 & Saluran Eksisting & 2,10 & 0,00141 & 0,22 & 2,32 \\
\hline 2 & $\begin{array}{l}\text { Saluran } 10 \text { tahun } \\
\text { mendatang }\end{array}$ & 2,48 & 0,00198 & 0,26 & 2,74 \\
\hline
\end{tabular}
aliran diperlihatkan pada Tabel 3

Tabel 3. Analisa debit aliran

Dari Tabel 3 dapat dilihat bahwa debit aliran pada saat penelitian dengan 10 tahun mendatang mengalami kenaikan ini disebabkan oleh perubahan tata guna lahan yang menyebabkan koefisien pengaliran $(C)$ semakin besar yang berbanding lurus dengan debit rencana aliran (Qr).

\section{Kapasitas Saluran}

Apabila kapasitas saluran lebih besar dari debit rencana aliran (Qs > Qr) maka saluran tersebut masih dapat menampung debit aliran yang terjadi. Tetapi apabila kapasitas saluran lebih kecil dari pada debit rencana aliran (Qs < Qr) maka saluran tersebut tidak mampu menampung debit aliran yang terjadi, sehingga perlu diadakannya perencanaan ulang terhadap dimensi saluran drainase. Perbandingan debit saluran drainase Jalan Arifin Ahmad pada ruas antara Jalan Rambutan dengan Jalan Paus Ujung dapat dilihat pada Tabel 4.

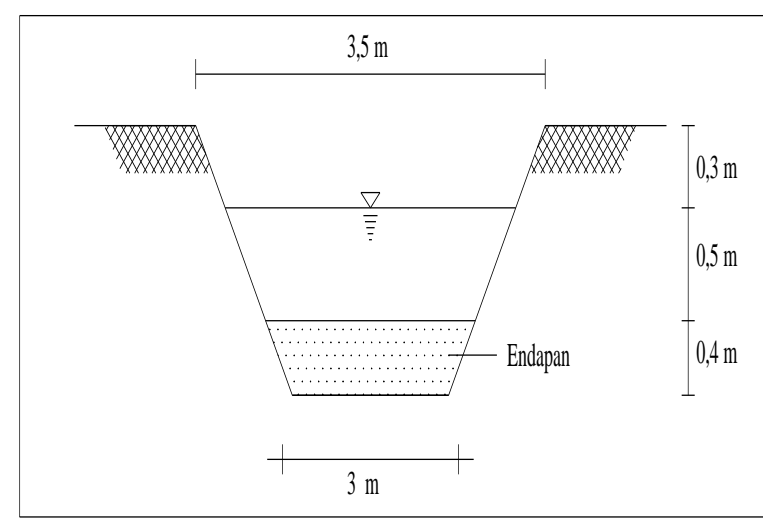

Gambar 5. Penampang saluran eksisting permanen 


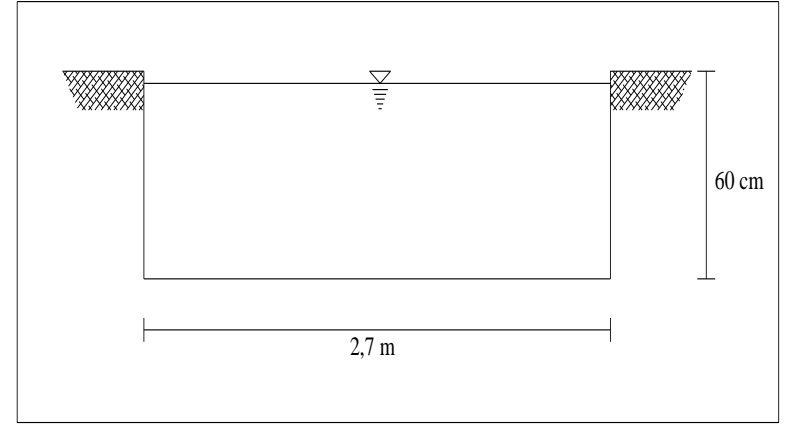

Gambar 6. Penampang saluran eksisting tanah

Dari Tabel 4, diketahui bahwa saluran drainase Jalan Arifin Ahmad pada ruas antara Jalan Rambutan dengan Jalan Paus tidak mampu menampung dan mengalirkan debit aliran yang ada, baik untuk saluran tanah maupun saluran permanen dan untuk waktu eksisting maupun 10 tahun mendatang. Untuk itu diperlukan perencanaan ulang dimensi saluran agar tidak terjadi genangan pada saluran tersebut.

Tabel 4. Perbandingan Q saluran dengan

\begin{tabular}{|c|c|c|c|c|}
\hline \multicolumn{5}{|c|}{ Q aliran } \\
\hline No & $\begin{array}{c}\text { Nama } \\
\text { Saluran }\end{array}$ & $\begin{array}{c}\mathbf{Q} \\
\text { Salu } \\
\text { ran } \\
\left(\mathbf{m}^{3} /\right. \\
\text { det })\end{array}$ & $\begin{array}{c}\mathbf{Q} \\
\text { Alira } \\
\mathbf{n} \\
\left(\mathbf{m}^{\mathbf{3}} / \mathbf{d}\right. \\
\text { et })\end{array}$ & $\begin{array}{l}\text { Kondisi } \\
\text { Saluran }\end{array}$ \\
\hline 1 & $\begin{array}{l}\text { Saluran } \\
\text { tanah } \\
\text { eksisting }\end{array}$ & 0,97 & 2,32 & $\begin{array}{l}\text { Tidak } \\
\text { Aman }\end{array}$ \\
\hline 2 & $\begin{array}{c}\text { Saluran } \\
\text { permanen } \\
\text { eksisting }\end{array}$ & 2,34 & 2,32 & Aman \\
\hline 3 & $\begin{array}{c}\text { Saluran } \\
\text { tanah } 10 \\
\text { tahun } \\
\text { mendatang }\end{array}$ & 0,97 & 2,74 & $\begin{array}{l}\text { Tidak } \\
\text { Aman }\end{array}$ \\
\hline 4 & $\begin{array}{l}\text { Saluran } \\
\text { permanen } \\
10 \text { tahun } \\
\text { mendatang }\end{array}$ & 2,34 & 2,74 & $\begin{array}{l}\text { Tidak } \\
\text { Aman }\end{array}$ \\
\hline
\end{tabular}

\section{Perencanaan Dimensi Ulang Saluran}

Untuk mengantisipasi terjadinya luapan atau genangan akibat tidak mampunya saluran drainase Jalan Arifin Ahmad pada ruas antara Jalan Rambutan dengan Jalan Paus menampung debit aliran yang ada, maka diperlukan perencanaan dimensi saluran yang baik, perhitungan dimensi saluran rencana dapat dilihat pada Tabel 5 dan untuk penampang saluran rencana dapat dilihat pada Gambar 4.

Tabel 5. Hasil perhitungan dimensi saluran drainase rencana

\begin{tabular}{|l|c|c|}
\hline \multicolumn{1}{|c|}{$\begin{array}{c}\text { Dimensi Saluran } \\
\text { Rencana }\end{array}$} & $\begin{array}{c}\text { Dimensi } \\
\text { Eksisting } \\
\text { Saluran } \\
\text { Permane } \\
\text { n }\end{array}$ & $\begin{array}{c}\text { Hasil } \\
\text { Perhitu } \\
\text { ngan }\end{array}$ \\
\hline Lebar atas saluran, B (m) & 3,5 & 3,5 \\
Lebar dasar saluran, b (m) & 3 & 3,5 \\
Kedalaman air, h (m) & 0,9 & 1,75 \\
Tinggi jagaan, w (m) & 0,3 & 0,25 \\
Tinggi saluran, H (m) & 1,2 & 2 \\
Kemiringan saluran, I (\%) & 1 & 0,07 \\
\hline
\end{tabular}

Berdasarkan hasil perhitungan di atas, maka gambar penampang saluran drainase rencana dapat dilihat pada Gambar 4.

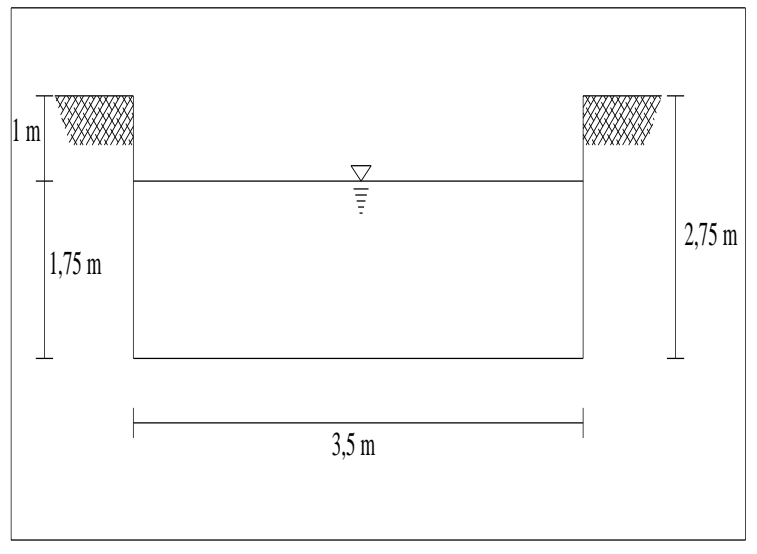

Gambar 7. Penampang saluran rencana sesuai dengan lebar eksisting

\section{KESIMPULAN}

Dari hasil analisa dan perhitungan pada bab-bab sebelumnya dapat diambil kesimpulan sebagai berikut:

1. Perubahan tata guna lahan menyebabkan bertambah besarnya koefisien aliran (C) dari eksisting 0,52 menjadi 0,62, dimana debit rencana aliran (Qr) 10 tahun mendatang menjadi $=2,74 \mathrm{~m}^{3} /$ detik dengan debit saluran (Qs) sebesar $=0,97$ $\mathrm{m}^{3} /$ detik untuk saluran tanah dan 2,34 
$\mathrm{m}^{3} /$ detik untuk saluran permanen. Adapun dimensi saluran drainase rencana 10 tahun mendatang berbentuk persegi, menyesuaikan keadaan eksisting dengan lebar dasar saluran $(B)=3,5 \mathrm{~m}$, tinggi permukaan air $(\mathrm{h})=1,75 \mathrm{~m}$, tinggi jagaan air $(\mathrm{w})=0,25 \mathrm{~m}$, dan tinggi saluran $(\mathrm{H})=2 \mathrm{~m}$.

2. Adapun faktor utama nya adalah debit rencana aliran lebih besar dari pada debit saluran eksisting, dimana debit rencana aliran $(\mathrm{Qr})=2,32 \mathrm{~m}^{3} / \mathrm{detik}$, debit saluran tanah eksisitng $(\mathrm{Qs})=0,97 \mathrm{~m}^{3} /$ detik, dan debit saluran permanen eksisting $(\mathrm{Qs})=$ $2,34 \mathrm{~m}^{3} /$ detik.

\section{DAFTAR PUSTAKA}

Badan Standarisasi Nasional, 2005. "Tata Cara Perencanaan Sistem Plambing”. SNI 03-7065-2005, Badan Standarisasi Nasional.

Bahri, Saipul, 2017. "Analisa Pengaruh Perubahan tata Guna Lahan Terhadap Kapasitas Drainase Di Jl. Arengka Kota Pekanbaru (Studi Kasus Pasar Pagi Arengka)". Tugas Akhir Program Strata 1 Teknik Sipil, Universitas Islam Riau, Pekanbaru-Riau.

Direktorat Jenderal Bina Marga, 2006. "Perencanaan Sistem Drainase Jalan". Departemen Pekerjaan Umum.

Hidayat, 2010. "Tinjauan Perencanaan Saluran Drainase Jalan Jati Kelurahan Tangkerang Utara Kota Pekanbaru-Riau". Tugas Akhir Program Strata 1 Teknik Sipil, Universitas Islam Riau, Pekanbaru-Riau.

Muslim, 2012. "Studi Perencanaan Sistem Drainase Jalan Terminal Mayang Terurai Kota Pekanbaru". Tugas Akhir Program Strata 1 Teknik Sipil, Universitas Riau, PekanbaruRiau.

Prima, Gama, 2015. "Kajian Kapasitas Saluran Pada Sistem Jaringan Drainase Untuk Mengatasi Genangan Di Jalan Raya Pekanbaru - Taluk Kuantan km 12
- km 13 Kabupaten Kampar”. Tugas Akhir Program Strata 1 Teknik Sipil, Universitas Islam Riau, Pekanbaru-Riau.

Putra, Niko Erdi, 2016. "Tinjauan Perencanaan Saluran Drainase Jl. Arifin Ahmad Kec. Marpoyan Damai Kota Pekanbaru". Tugas Akhir Program Strata 1 Teknik Sipil, Universitas Islam Riau, Pekanbaru-Riau.

Rachman, Rizka dkk, 2014. "Studi Pengendalian Banjir di

Kecamatan Kepanjen Dengan Sumur Resapan". Malang: Jurnal Pengairan. Vol. 5, No. 1:79-90

Rapar, Sharon dkk, 2014. "Analisis Debit Banjir Sungai Tondano Menggunakan Metode HSS Gama I dan HSS Limantara". Manado: Jurnal Sipil. Vol. 2, No. 1:13-21.

Rianda, Rizki, 2016. "Analisis Perubahan Tata Guna Lahan Terhadap Koefisien Limpasan Kota Pekanbaru Berbasis Sistem Informasi Geografis (SIG)". Tugas Akhir Program Strata 1 Teknik Sipil, Universitas Riau, PekanbaruRiau

Soemarto, 1993. "Hidrologi Teknik". Erlangga, Jakarta.

Suhardjono dkk, 2014. "Studi Pengendalian Banjir di Kecamatan Kepanjen Dengan Sumur Resapan". Universitas Brawijaya, MalangJawa Timur.

Suripin, 2004. "Sistem Drainase Perkotaan yang Berkelanjutan". Andi Offset, Yoyakarta.

Suprayogi, Imam dkk. 2017. "Analisis Pengaruh Perubahan Tata Guna Lahan Terhadap Saluran Drainase Jalan Dprak Berdasarkan Pola Rencana Tata Ruang Tata Wilayah Kabupaten Meranti Tahun 20132032 Menggunakan Model Epa Swmm 5.0". Pekanbaru: Jurnal Saintis. Vol. 17, No. 1:1-14.

Syafrianto dkk, 2013. "Evaluasi Sistem Drainase Jalan Lingkar Boter 
Kabupaten Rokan Hulu”. Rokan

Hulu: Jurnal Sipil. Vol.1, No. 1

Wesli, 2008. "Drainase Perkotaan". Graha

Ilmu, Yogyakarta.

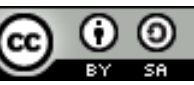

This is an open access article which means that all content is freely available without charge to the user or his/her institution. Jurnal Saintis allows the author(s) to hold the copyright without restriction. The copyright in the text of individual articles (including research articles, opinion articles, and abstracts) is the property of their respective authors distributed under the terms of the Creative Commons Attribution-ShareAlike 4.0 International License(https://creativecommons.org/licenses/by-sa/4.0/) which permits unrestricted use, distribution, and reproduction in any medium. Users are allowed to read, download, copy, distribute, search, or link to full-text articles in this journal without asking by giving appropriate credit, provide a link to the license, and indicate if changes were made. 